ISSN electrónico: 1585-5210

DOI: https://doi.org/10.14201/rmc.27919

\title{
EL SÉPTIMO SELLO (1957), ENTRE PESTES Y SINDEMIAS
}

\section{The Seventh Seal (1957), Between Plagues and Syndemics}

\author{
Francisco Ignacio MORETA VELAYOS; Carolina MORETA MONTERO; Flori SÁNCHEZ DE LA MANO; \\ Carmen RAMÍREZ ORIBE; Manuela Alina SICA SICA; Nieves MONTERO SÁNCHEZ \\ Centro de Salud Parque Coímbra. Móstoles. Servicio Madrileño de Salud (España). \\ Autor para la correspondencia: Francisco Ignacio Moreta Velayos. \\ Correo electrónico: fimoreta@yahoo.es
}

Recibido: 31 de mayo de 2021

Aceptado: 26 de julio de 2021

\section{Resumen}

Tal que, a otros muchos, sin duda, con el inicio de los confinamientos decretados para intentar contener la actual pandemia, nos vino a la cabeza El séptimo sello (1957) de Bergman, relacionando los acontecimientos del tiempo en que se desarrolla la película con los que vivíamos y vivimos actualmente: la epidemia de Peste Negra que asolaba Suecia en el siglo XIV de un lado y la pandemia por Covid-19 de otro, sindemias ambas como algunos prefieren Ilamarlas.

Tomando como disculpa la obra de Ingmar Bergman nuestra pretensión es hacer algunas comparaciones entre la peste medieval y la pandemia actual aportando algunas reflexiones y opiniones personales surgidas muchas de ellas de nuestra propia experiencia durante estos largos meses.

Palabras clave: Peste negra; covid-19; pandemia; sindemia; silencio.

\section{Abstract}

Such as many others, without question, the beginning of the decreed lockdowns to contain the current pandemic, Bergman's The Seventh Seal (1957) came to our minds, relating the film time events with the current ones: the Black Death pandemic which isolated Sweden in XIV on one hand, and Covid-19 pandemic on the other, both syndemics as some prefer to name them. 
Using Ingmar Bergman's work as a reference, our aim is to make comparisons between the medieval plague and the actual pandemic, contributing with some reflections and personal opinions, many of them emerged from our own personal experience during these long months.

Keywords: Black death; covid-19; pandemic; syndemic; silence.

Cuando soltó el séptimo sello se hizo silencio en el cielo por cosa de media hora. $V i$ a los siete ángeles que están delante de Dios; les dieron siete trompetas.

Apocalipsis 8,1-2 ${ }^{1}$

\section{Ficha técnica}

Título: El séptimo sello.

Título original: Det sjunde inseglet.

Año: 1957.

País: Suecia.

Director: Ingmar Bergman.

Música: Erik Nordgren.

Fotografía: Gunnar Fischer (B\&W).

Montaje: Lennart Wallén.

Guión: Ingmar Bergman.

Interpretes: Gunnar Björnstrand, Bengt Ekerot, Nils Poppe, Max von Sydow, Bibi Andersson, Inga Gill, Maud Hansson, Inga Landgré, Gunnel Lindblom, Bertil Anderberg, Anders Ek, Åke Fridell, Gunnar Olsson, Erik Strandmark.

Idioma original: Sueco.

Color: Blanco y negro.

Duración: 96 minutos.

Género: Drama. Siglo XIV. Edad Media. Religión. Ajedrez. Pandemias.

Película de culto.

Productora: Svensk Filmindustri (SF).

Sinopsis: Antonius Block es un caballero que acaba de volver de la Cruzada junto a su escudero Jöns; ambos llegan a su tierra natal, Suecia, que está devastada por la peste negra. Al comienzo de la película, Block reta a la Muerte a una partida de ajedrez para intentar salvar su vida: si le gana, no tendrá que irse con ella. El séptimo sello / Det sjunde inseglet, 1957 gira en torno a los encuentros entre estos dos personajes, Block y la Muerte, quienes mantienen conversaciones sobre la existencia de Dios, su silencio, el sufrimiento, el sentido de la vida... Estos temas acentúan la atmósfera apocalíptica que tiene toda la película, siendo la principal materia el silencio de Dios, su ausencia y el desamparo del hombre solitario.

Premios: 1957: Festival de Cannes: Premio Especial del Jurado (Ex aequo con "Kanal").

\section{Enlaces:}

https://www.filmaffinity.com/es/film723978. html

http://cine.estamosrodando.com/peliculas/ el-septimo-sello/ficha-tecnica-ampliada/

https://www.um.es/educarlamirada/?cine =al-son-de-la-muerte

Tráiler 
EL SÉPTIMO SELLO (1957), ENTRE PESTES Y SINDEMIAS

FRANCISCO IGNACIO MORETA VELAYOS; CAROLINA MORETA MONTERO; FLORI SÁNCHEZ DE LA MANO; CARMEN RAMÍREZ ORIBE; MANUELA ALINA SICA SICA; NIEVES MONTERO SÁNCHEZ

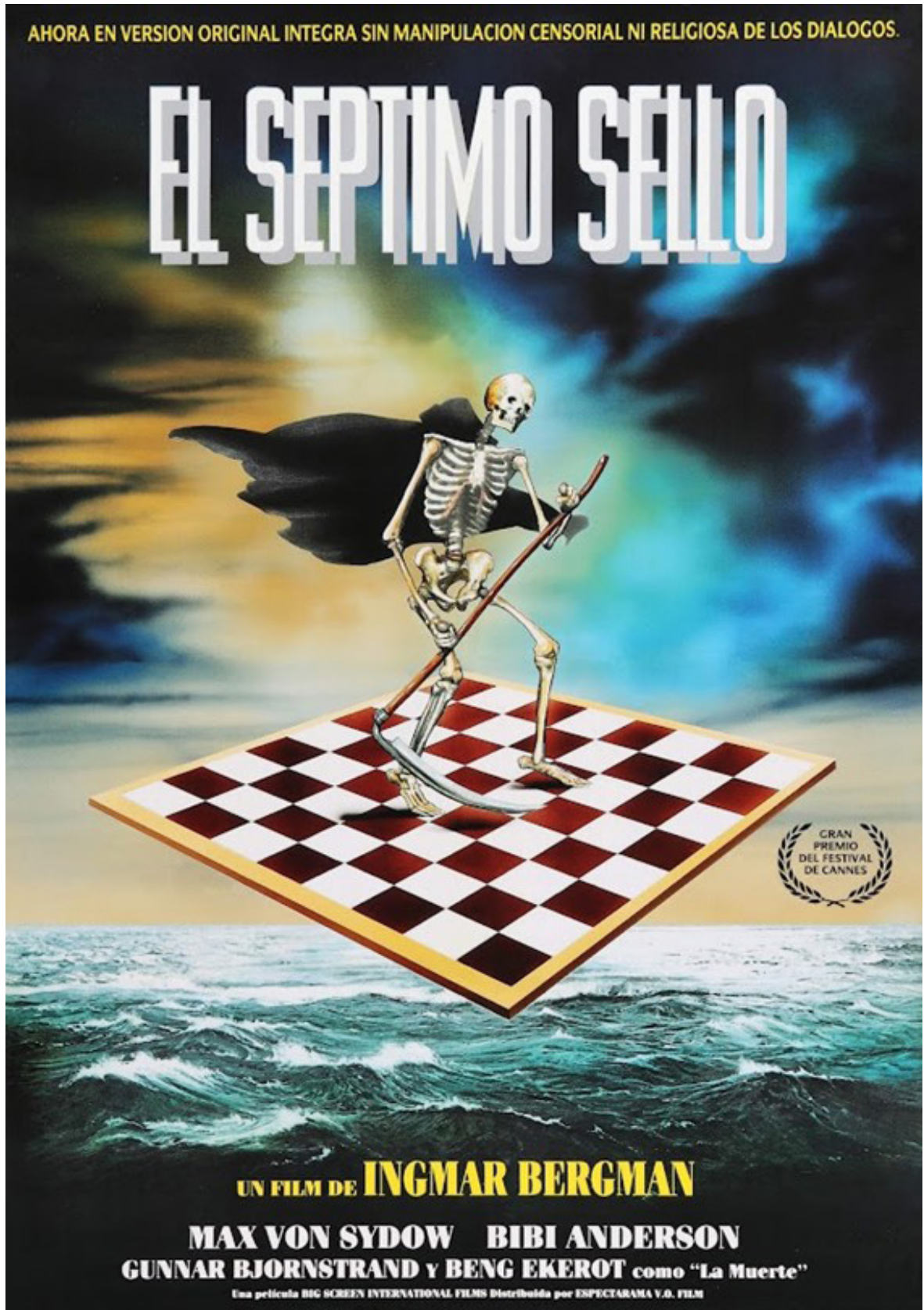

Cartel de El Séptimo sello. España 


\section{¿Pestes, pandemias o sindemias?}

Durante los primeros meses de la actual pandemia por el coronavirus, ante las noticias de que determinados personajes de la alta sociedad, políticos u otros famosos habían sido afectados por la enfermedad en distintos puntos del mundo, se extendió la idea de que ésta no hacia distingos sociales y de que todos corríamos el mismo riesgo de padecerla e incluso de morir; después, como en el caso de la peste y otras epidemias, hemos podido ver que no es así y que tanto los efectos directos del virus como los colaterales no afectan de la misma forma a los distintos estratos sociales y comunidades. En apoyo de esta idea, nos ha parecido interesante hacer referencia a determinados términos utilizados para aludir a fenómenos similares pero que pueden sugerir un enfoque distinto de la situación que nos ocupa.

El término peste hace alusión a una enfermedad infectocontagiosa definida (peste negra) y con un agente causal actualmente perfectamente identificado, pero de forma genérica también nos referimos a "afecciones de muy diversa naturaleza, que reúnen la característica común de alterar la salud rápidamente en un número progresivamente mayor de individuos» ${ }^{2}$. Con esta palabra y otras como pestilencia también hacemos alusión a un olor intenso y especialmente desagradable que se extiende por una zona amplia y que a su vez nos llevaría a pensar en los miasmas como responsables de la enfermedad.

Pandemia es un término epidemiológico que hace alusión a la declaración por parte de las autoridades sanitarias de la Organización Mundial de la Salud (OMS) de un estado en el cual un brote epidémico de una enfermedad infecciosa afecta a más de un continente y en el cual hay además transmisión intracomunitaria ${ }^{3}$. Visto así parece claro que la Peste bubónica fue también una pandemia puesto que afectó a la mayor parte del mundo conocido en aquel momento, que además como la Covid-19 también es una zoonosis y que los actuales miasmas serían los aerosoles, ambos viajarían por el aire, si bien sabemos que la Peste no se transmite por este medio salvo de forma excepcional.

Respecto a las sindemias, cuando los resultados de una pandemia sobre los individuos y la sociedad se ven afectados o son consecuencia de la interacción con comorbilidades previas (diabetes, hipertensión, obesidad, EPOC) u otros aspectos socioeconómicos, políticos o ecológicos, nos encontraríamos ante una sindemia (neologismo que nace de la unión de sinergia y epidemia), noción concebida por primera vez por Merrill Singer en la década de 1990 argumentando que "un enfoque sindémico revela interacciones biológicas y sociales que son importantes para el pronóstico, el tratamiento y la política de salud $»^{4,5}$.

Sin entrar ahora en detalles específicos, si echamos una mirada a la historia de la Peste Negra (existen múltiples publicaciones más o menos extensas, algunas referenciadas al final ${ }^{2}$, $\left.{ }^{6,7}\right)$ o a la crónica diaria a nivel mundial de la pandemia provocada por el SARS-CoV-2, no queda duda que nos encontramos en ambos casos ante zoonosis y sindemias que, teniendo un origen animal y unas circunstancias medioambientales determinadas se diseminan por todo el planeta gracias a la movilidad humana, más rápidamente en nuestros días. Admitir e interiorizar éste término y su significado sería un importante avance en el abordaje de la situación actual y otras que parecen inevitables vendrán en el futuro. Así lo propugnan distintos movimientos como el One Healt ${ }^{8}$, que propone entre otras medidas el cambio en nuestra forma de relacionarnos con los animales y la naturaleza en su conjunto.

\section{De la Peste Negra a la Covid-19}

Intentando buscar analogías entre El séptimo sello y la situación actual, el silencio ${ }^{9}$, como en el Apocalipsis, es el término y la situación que mejor las definiría; más allá de los aspectos médicos, epidemiológicos o sociales. 
El silencio - y la soledad e incomunicación en las calles y carreteras, en las casas, en nuestras habitaciones, en las residencias de ancianos y hospitales y, la falta de respuestas, como le sucede al caballero Antonius en la película, a la infinidad de interrogantes ante lo que nos estaba sucediendo o estaba por venir y esto, pese al exceso de información o desinformación que nos llegaba por múltiples canales y procedente de distintas fuentes.

Silencio frente al horror de las imágenes que se nos presentaban y a los temores que surgían en nuestras cabezas y que posiblemente no siempre confesábamos: nuestra fragilidad y finitud, sobre el sentido de la vida. Un silencio agobiante que, tal que en el Apocalipsis "por cosa de media hora», se alargaba de forma inquietante ante la incertidumbre "y la adversidad inherentes a toda vida humana $»^{10}$, recurriendo a la argucia de los aplausos de las ocho a "los héroes de la pandemia» como forma de exorcizarlo, de tomarnos un respiro y descargar nuestra ansiedad (Foto 1).

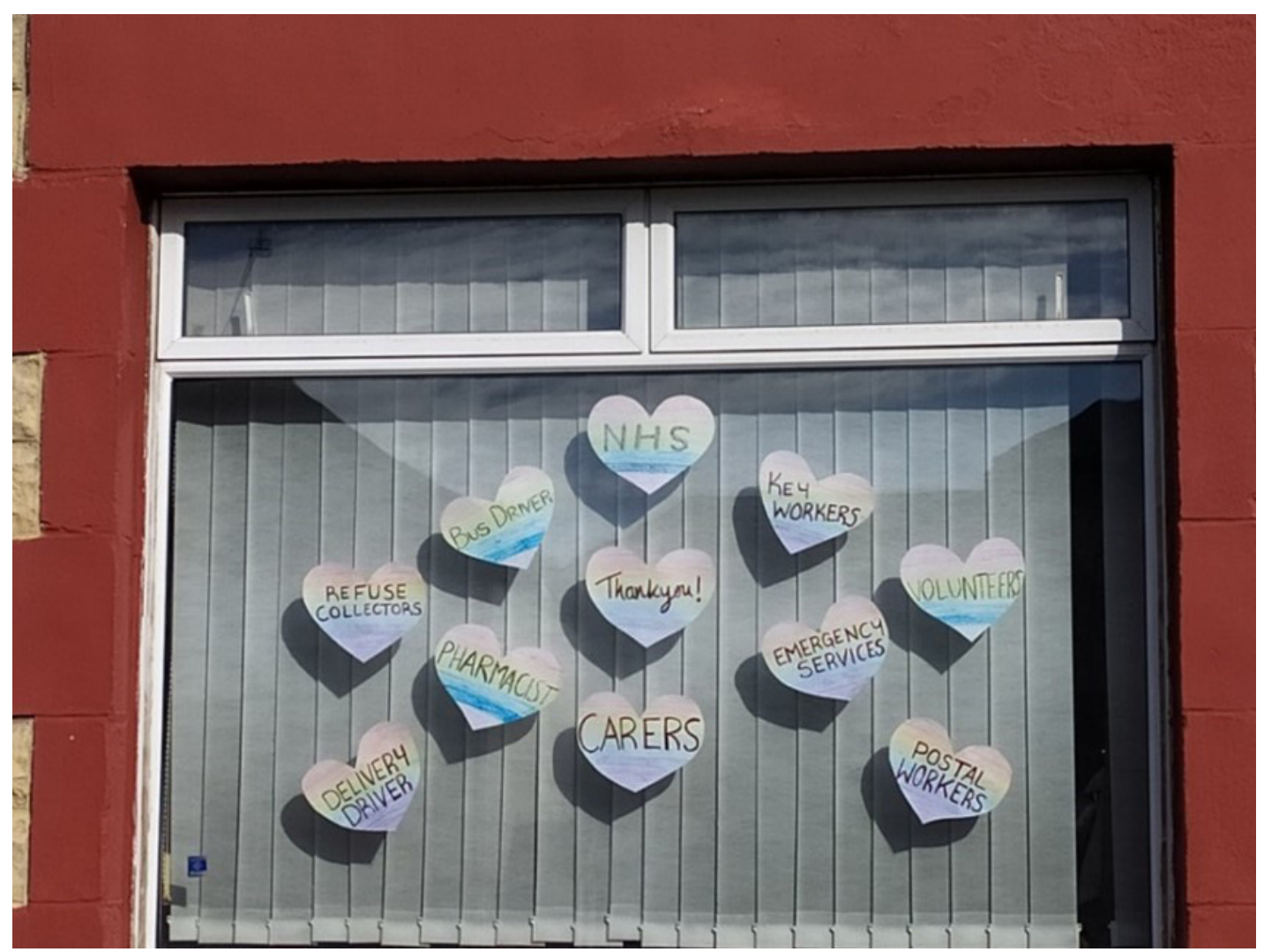

Foto 1. Ventana en Edimburgo al inicio de la Covid-19 en 2020 
Buscando similitudes, es importante sin duda el comportamiento del ser humano cuando se siente amenazado; que va desde la negación al inmovilismo, la huida y el egoísmo en muchos casos a la resistencia audaz ante lo desconocido y la generosidad en otros. Lo encontramos tanto en la cinta y en la historia de la peste negra como en la situación actual; hemos sometido a cuarentena y aislamiento a los pacientes y cuidadores más allá de la prevención; llegando a la estigmatización de los enfermos y al señalamiento de los profesionales, mientras éstos se escudaban con bolsas de basura y se iban a vivir fuera de sus casas para proteger a los suyos.

Otra coincidencia curiosa es el hecho de que ante cualquier tipo de problema que nos sobrepasa siempre tranquiliza encontrar un "chivo expiatorio». La pérdida de El Paraíso, la peste negra y la actual pandemia tienen uno en común, la mujer: en el primer caso Eva fue la responsable de aquella catástrofe que nos marcó para los restos, en el segundo las brujas que no en pocas ocasiones terminaron en la hoguera y en el caso actual, las feministas y sus manifestaciones, al menos en nuestro país ${ }^{11}$.

Como en el caso de la peste, también ahora, China con sus mercados húmedos de animales ha sido el origen desde el cual la pandemia se ha extendido al resto del mundo, proporcionando a políticos y ciudadanos un buen argumento para cargar contra ése país que pretende dominar a todo el orbe; primero crean y difunden el virus para seguidamente fabricar la vacuna con la cual, aparte de hacerse con el poder económico intentarán dominar nuestras mentes.

A propósito de políticos y estrategas; además de las dantescas escenas de los cadáveres amontonados en las improvisadas morgues en todo el mundo o las incineraciones públicas que vemos estos días en India, hemos podido presenciar las batallas dialécticas de nuestros representantes en las que han utilizado a los muertos como arma arrojadiza igual que hicieron con los cadáveres de los apestados los tártaros en el año 1346 durante el asedio de ciudad de Kaffa ${ }^{6}$, estrategia que hasta donde sabemos no tuvo la efectividad esperada; esperemos que ahora tampoco.

Imitando a los protagonistas de El Decamerón en tiempos de la peste, ahora hemos intentado poner distancia con las zonas supuestamente más peligrosas saliendo en desbandada hacia las costas y el campo; finalmente hemos perdido el miedo sumándonos a los que propugnan el carpe diem; la macabra danza de la muerte que hemos visto cada fin de semana en nuestras ciudades o con el fin del estado de alarma.

$Y$ aunque era opinión unánime el que de ésta saldríamos mejores, con el paso de los meses ha sucedido como se refiere en el Libro de las Revelaciones: "El resto de los hombres, los que no murieron por estas plagas, tampoco se arrepintieron: [...] de sus homicidios, ni de sus maleficios, ni de su lujuria ni de sus robos» (Apocalipsis 9, 20-21) ${ }^{1}$.

Otra cualidad que compartimos con la antigua sindemia es la ignorancia; utilizada incluso como forma de defensa frente a la ansiedad.

En los tiempos de la peste negra fueron múltiples las hipótesis respecto a su origen: judíos, brujas, fenómenos astrológicos, etc., siendo la teoría de los miasmas la que más adeptos sumó pese a evidencias más plausibles que otros sostenían ${ }^{2,7}$. En el caso de la Covid-19 aunque desde el principio supimos que el coronavirus era el responsable de la misma no han faltado las especulaciones xenófobas, negacionistas o conspiranoicas. En todo caso, seguimos sin saber cómo el virus salto de los animales al ser humano o, como defienden otros, si se escapó o se difundió de forma intencionada desde un laboratorio.

Ignorancia en cuanto a la prevención o tratamiento, con propuestas tan exotéricas como la ingesta de lejía recomendada por algún dirigente mundial. En otro orden de cosas, aunque desde los tiempos de la peste sabíamos que los movimientos de las personas están en la base de la diseminación de las pandemias, lo ignoramos y según los expertos fuimos excesivamente lentos a la hora de tomar medidas al respecto ${ }^{12}$. 
Al igual que en la película, también ahora tenemos nuestra propia partida de ajedrez contra la Muerte (Foto 2) con la esperanza de vencer a la pandemia, de aplazar lo inevitable, de seguir a lo nuestro y no tanto posiblemente, de intentar buscar respuestas a los dilemas existenciales.

Nuestras piezas más importantes en juego no son las procesiones de flagelantes o los jubileos (Foto 3), la quema de brujas o expulsión de extranjeros - que también -, son la juventud, los tratamientos médicos y sobre todo las vacunas. Queremos un tiempo más, una nueva oportunidad para volver a vivir como antes de la pandemia, sin que nada cambie. Y pretendemos ganar la partida a cualquier precio, sin pensar en los millones de personas que se quedan por el camino. Buscamos el beneficio inmediato, hedonista o lucrativo, billonario en determinados casos.

A modo de conclusión y con una perspectiva de futuro parece aconsejable recordar que "las infecciones han sido la causa principal de mortalidad desde que el hombre recuerda y piensa, más letales que las hazañas bélicas de los hombres, los colapsos de la economía o las venganzas de la Naturaleza» ${ }^{13}$.

Ante la situación actual, no deberíamos mirar hacia otro lado y caer en el error de olvidar que tratándose de una sindemia, ha de abordarse en toda su complejidad más allá de los aspectos puramente médicos o económicos. Eventualmente, entre la avalancha diaria de

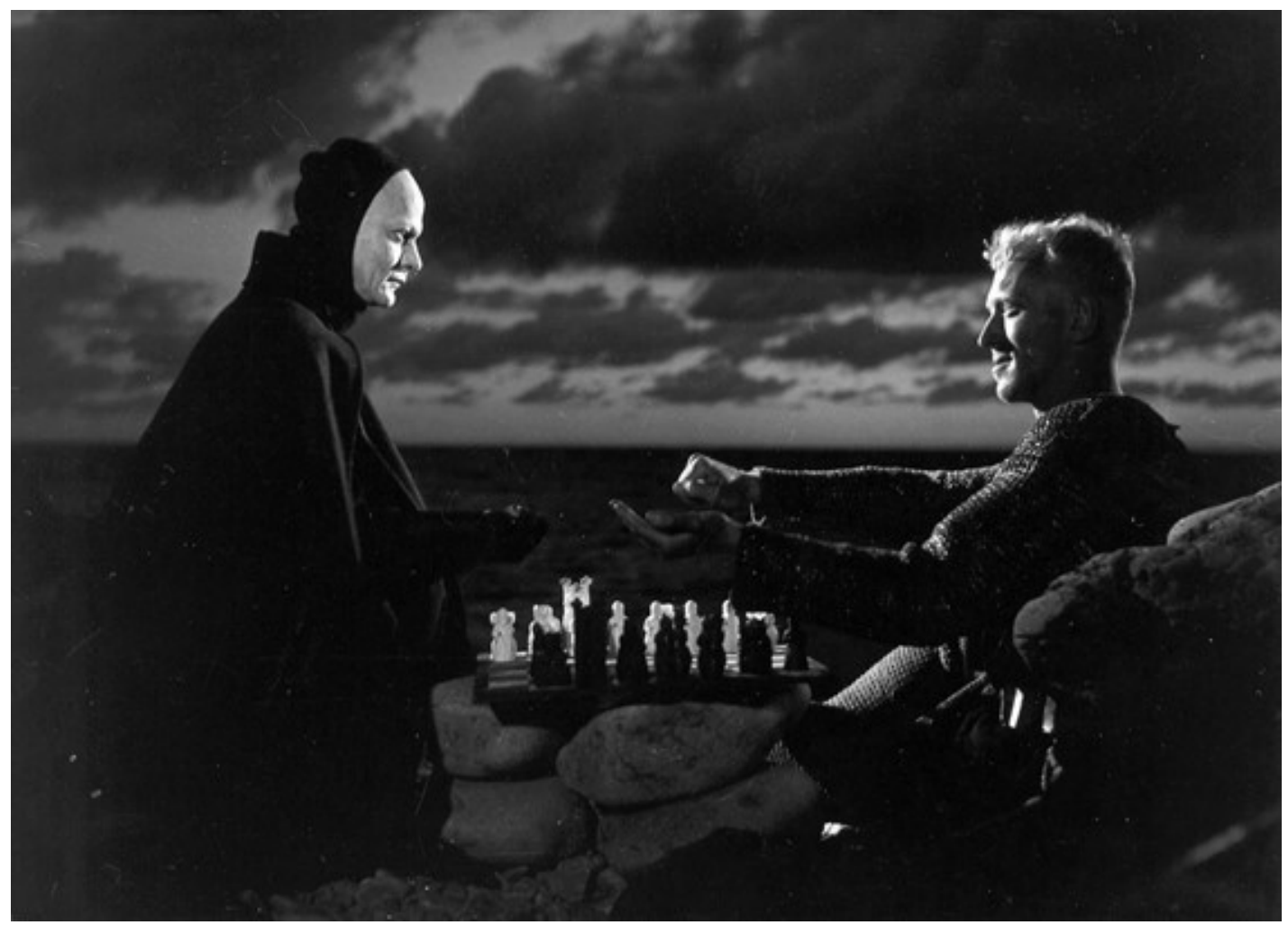

Foto 2. Antonius juega al ajedrez con la muerte. Fotograma de El séptimo sello 


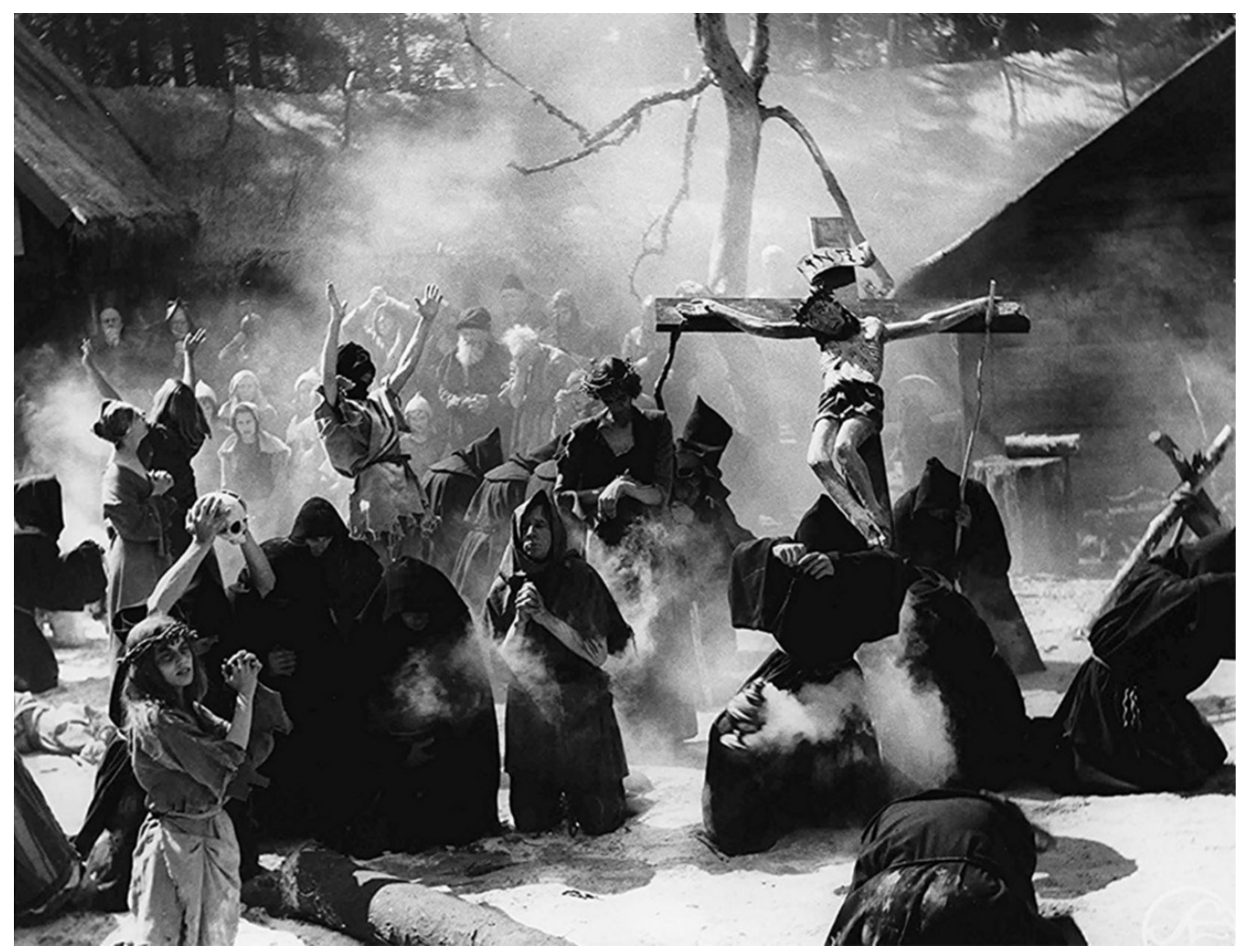

Foto 3. Procesión de flagelantes. Fotograma de El séptimo sello

noticias, destacar las recientes conclusiones del panel independiente de expertos de la OMS en las que la ex presidenta de Liberia, Ellen Johnson Sirleaf, afirma que: "El sistema actual falló en protegernos de la pandemia de la Covid-19. Y si no actuamos para cambiarlo ahora, no nos protegerá de la próxima amenaza pandémica, que podría ocurrir en cualquier momento» ${ }^{12}$.

\section{La alternativa de Bergman}

Es el amor; ante el silencio, la soledad e incomunicación y la incertidumbre, nos ofrece la alternativa del amor, en El séptimo sello representado por la pareja de acróbatas Mia y Jof, con su bebé Mikael que a la vez que se aman entre ellos, aman y ayudan desinteresadamente a los que se cruzan en el camino en su recorrido por la vida. (Foto 4)

El altruismo y la generosidad - con las vacunas, v.g. - con los menos favorecidos como forma de amor evitando los codazos en ser los primeros por conseguir los remedios o sacar cualquier tipo de rédito, incluso egoístamente pues, lo hemos oído repetidas veces, de ésta salimos juntos o no salimos. No confundiendo "la felicidad con la comodidad y el materialismo, y aceptar disminuir un estilo de vida confortable, pero destructivo» ${ }^{10}$. 


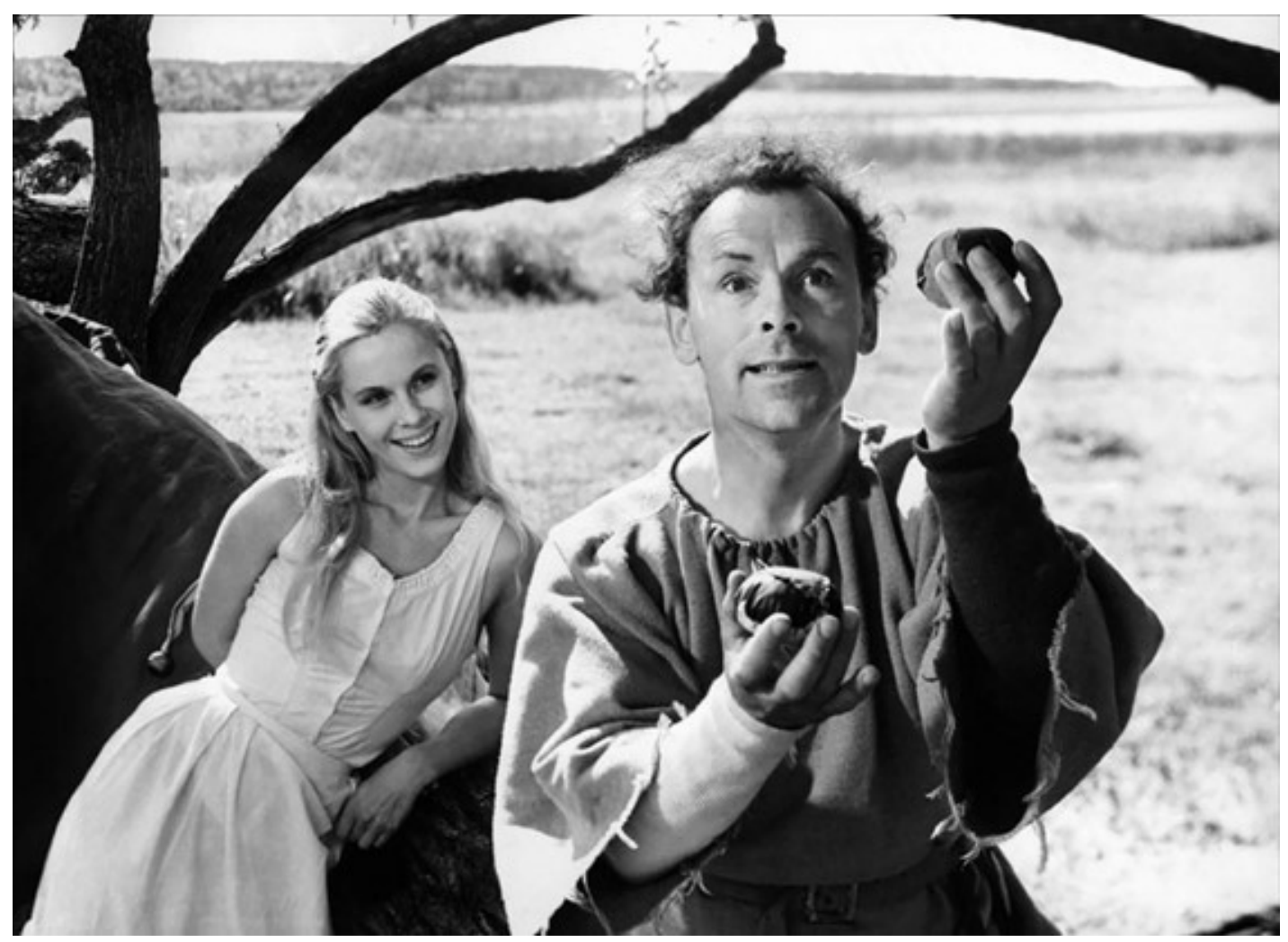

Foto 4. Pareja de acróbatas. Fotograma de El séptimo sello

\section{Agradecimientos}

A todas y a todos los trabajadores del C. S. Parque Coímbra que en tantos momentos de agotamiento e incertidumbre, desde el inicio de la pandemia, han preservado el máximo nivel de profesionalidad, soporte mutuo y generosidad. A Nieves y a las voluntarias y voluntarios por su apoyo y humanidad.

\section{Referencias}

1. Mateos J. (traductor). Nuevo Testamento. Madrid: Ediciones Cristiandad; 1975.

2. Carreras Pachón A. Miasmas y retrovirus. Barcelona: Fundación Uriach 1838; 1991.
3. Pulido S. ¿Cuál es la diferencia entre brote, epidemia y pandemia? Gaceta Médica. [Internet]. 12 de marzo de 2020. [Citado el 1 de febrero de 2021]

4. Horton R. Offline: COVID-19 is not a pandemic. Lancet. 396 (10255): 874. doi: 10.1016 / S0140-6736 (20) 32000-6.]

5. Alba Rico S. Capitalismo pandémico. Ctxt. [Internet]. 2021;(268). [Citado el 4 de febrero de 2021]

6. Álvarez J. Cuando los mongoles trataron de conquistar Caffa lanzando cadáveres infectados de Peste Negra. La Brújula Verde. [Internet]. 18 de agosto de 2018. [Citado el 15 de febrero de 2021]

7. D'Ottavio ME, D'Ottavio GE, D'Ottavio AE. La peste negra del siglo XIV en el cine. Rev. Med. Cine. 2020; 16 (e), 351-361. 


\section{EL SÉPTIMO SELLO (1957), ENTRE PESTES Y SINDEMIAS}

FRANCISCO IGNACIO MORETA VELAYOS; CAROLINA MORETA MONTERO; FLORI SÁNCHEZ DE LA MANO;

CARMEN RAMÍREZ ORIBE; MANUELA ALINA SICA SICA; NIEVES MONTERO SÁNCHEZ

8. Rodríguez Ferri E. Calvo Sáez L. Zoonosis. La cara oculta de la pandemia Covid-19. Rev. Med. Cine. 2020; 16 (e), 247-259.

9. Agudelo Ramírez M. El séptimo sello. Una mirada fílmica sobre el silencio de Dios. Ética \& Cine. 2018; 8 (1), 9-15.

10. André C. La incertidumbre invita a la sabiduría. Investigación y ciencia. Mente y cerebro. [Internet]. 2021; (108):16-19. [Citado el 19 de mayo de 2021]
11. González C. ¿EE 8-M, el culpable de todos los males? Viajemos al pasado para analizar la demagogia de la derecha con el coronavirus. Público. [Internet]. 28 de marzo de 2020. [Citado el 12 de febrero de 2021]

12. Linde P. Informe de los expertos para la OMS: «La catástrofe de la covid se podría haber evitado». El País. [Internet]. 12 de mayo de 2021. [Citado el 20 de mayo de 2021]

13. Palomés J. Sobre los virus y otros invisibles. Ctxt. [Internet]. Diciembre 2020; (267) [Citado el 10 de febrero de 2021] 